\title{
Correction of Defective Host Response to Mycobacterium Bovis BCG Infection in TNF-Deficient Mice by Bone Marrow Transplantation
}

\author{
Muazzam Jacobs, Mike W. Marino, Najmeeyah Brown, Brian Abel, \\ Linda-Gail Bekker, Valerie J.F. Quesniaux, Lizette Fick, and Bernhard Ryffel
}

Department of Immunology (MJ, NB, BA, L-GB, VJFQ, LF, BR), University of Cape Town, South Africa; and Ludwig Institute for Cancer Research (MWM), New York Branch at Memorial Sloan-Kettering Cancer Center, New York

\begin{abstract}
SUMMARY: Tumour necrosis factor- $\alpha$ (TNF) plays a central role in the recruitment and activation of mononuclear cells in mycobacterial infection. In the absence of type 1 TNF receptor, Mycobacterium bovis Bacillus Calmette-Guérin (BCG) infection of mice is not contained, leading to fatal disease. Because type 1 TNF receptor binds both TNF and lymphotoxin- $\alpha$, we used TNF-deficient mice to determine the specific role of TNF in the host resistance to BCG infection. The bacterial burden of the lungs of TNF-deficient mice was substantially increased and the mice succumbed to pneumonia between 8 and 12 weeks with a defective granuloma response. Atypical granulomas developed by 4 weeks expressing low levels of MHC class II, intracellular adhesion molecule (ICAM-1), CD11b and CD11c. Macrophages showed little signs of activation and had low levels of acid phosphatase activity and inducible nitric oxide synthase (INOS) expression. Despite the defective cellular recruitment, the chemokines, monocyte chemoattractant protein-1 (MCP-1) and macrophage inflammatory protein-1 (MIP-1 $\alpha)$, were increased in broncho-alveolar lavage fluid of TNF-deficient mice. The defective host response was corrected by the transplantation of normal bone marrow cells into irradiated TNF-deficient mice. These results demonstrate that TNF derived from hemopoietic cells rather than from mesenchymal origin are essential for a normal host response to BCG infection. Furthermore, TNF dependent expression of adhesion molecules may be essential for the recruitment of mononuclear cells for the formation of bactericidal BCG granulomas. (Lab Invest 2000, 80:901-914).
\end{abstract}

Proth rotective immunity to $M$. tuberculosis infection, both in humans and experimental animals, is regulated by cytokines, which include IFN $\gamma$ and tumour necrosis factor- $\alpha$ (TNF). IFN $\gamma$ derived from $\mathrm{T}$ and NK cells has been shown to be essential, as mice with a disruption of the IFN $\gamma$ system are unable to restrict the growth of $M$. tuberculosis and succumb to the infection (Cooper et al, 1993, 1995, 1997; Flynn et al, 1995; Kamijo et al, 1993a; 1993b). In humans, deficiencies of IFN $\gamma$ receptor (De Jong et al, 1998) and IL-12 receptor (Altare et al, 1998) are associated with a predisposition to mycobacterial infections. TNF was shown to be induced in human and experimental tuberculosis (Bloom, 1994). The role of TNF in mycobacterial defence is inferred from neutralization and deletion experiments in mice (Flynn, et al, 1995; Senaldi et al, 1996). Neutralization of TNF with rabbit anti-TNF was shown to prevent the formation of bactericidal granulomas in BCG infected mice (Kindler et al, 1989). However, it is not clear whether these experiments distinguished between the effects of TNF

Received February 23, 2000.

This work was supported by the Wellcome Trust, Action TB Glaxo, MRC grant 41538 and Harry Crossley Fund 435873, Cape Town.

Address reprint requests to: Dr. Bernhard Ryffel, Department of Immunology, University of Cape Town, South Africa. Fax: 002721448 6116; Email:bryffel@uctgsh1.uct.ac.za and lymphotoxin- $\alpha(L T)$, since the specificity of the polyclonal serum for TNF versus LT has not been documented. Experiments in which either soluble TNF-receptor 1 (sTNF-R1) or TNF-R1-deficient mice were used (Flynn, et al, 1995; Senaldi, et al, 1996) indicated that TNF, LT, or a synergistic action of both, influenced granuloma formation in response to BCG, because TNF-R1 conveyed signals from both ligands. Therefore, these previous data do not allow the distinction between the roles of TNF and LT in host resistance against mycobacterial infection.

TNF/LT double-deficient mice display a complete disruption of the TNF system, with no signaling through the TNFR-1, TNFR-2, and the LT $\beta$-R (Eugster et al, 1996). Using these mice, we demonstrated that absence of both the TNF and LT ligand leads to fatal $B C G$ infection (in press). However, investigations in TNF/LT double-deficient and LT deficient mice are complicated by the fact that these mice have major developmental abnormalities of the peripheral immune system.

In this study, we investigated the specific role of TNF in containing an infection with $M$. bovis BCG (unlike M. tuberculosis, M. bovis is non-pathogenic in immuno-competent mice) by using TNF-deficient mice (Marino et al, 1997). Our data demonstrate that a disruption of the TNF gene impairs the formation of bactericidal granulomas in liver and lung, allowing the fatal spread of the BCG infection in TNF-deficient 
mice. Furthermore, correction of TNF-deficiency by bone marrow transplantation suggests that effector cells of hemopoietic origin are sufficient to confer TNF-dependent host resistance to $M$. bovis BCG infection.

\section{Results}

\section{Mice Deficient for TNF-R1 or TNF Succumb to BCG Infection}

We compared the resistance to BCG of TNF-R1deficient mice with the resistance to BCG of wild-type mice. Four weeks after infection, TNF-R1-deficient mice injected with $10^{7} \mathrm{BCG}$ bacilli developed only very small granulomas in the liver. These mice had an increased bacterial burden as compared with wildtype mice (data not shown) and they succumbed to infection as early as 5 weeks after infection, whereas all wild-type mice survived (Fig. 1). These findings are in accordance with earlier experiments using either neutralizing antibodies or soluble TNF-R1 to block the TNF pathway (Flynn, et al, 1995; Kindler, et al, 1989; Senaldi, et al, 1996).

As both TNF and LT signal through TNF-R1, we investigated whether host resistance is mediated by TNF alone by using TNF-deficient mice (Marino, et al, 1997). Unlike the LT-deficient mice (Banks et al, 1995; De Togni et al, 1994), TNF-deficient mice have no developmental abnormalities of the immune system. TNF-deficient mice were injected intravenously with $10^{7}$ BCG bacilli. Mice died from pneumonia within 8 to 12 weeks after infection (Fig. 1), whereas wild-type mice survived the 12-week experiment. The present data confirm that TNF signaling through TNF-R1 is indispensable in controlling a BCG infection.

\section{Uncontrolled Bacterial Growth in the Lung of TNF-Deficient Mice}

Since TNF-deficient mice succumb to infection, we examined the extent that TNF was required to control

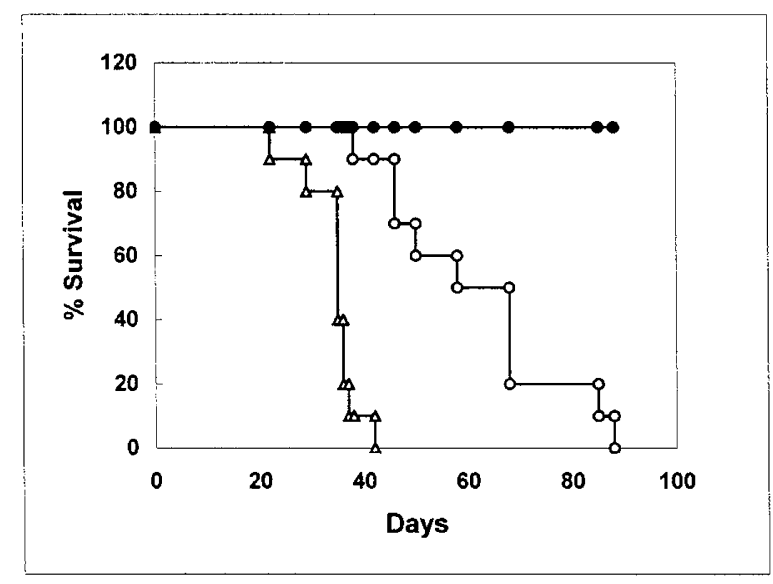

Figure 1.

Survival of TNF-deficient and TNF-R1-deficient mice infected with $M$. bovis BCG. TNF-deficient $(o)$, TNF-R1 deficient mice $(\Delta)$ and wild-type mice $(\bullet)$ were infected intravenously with $10^{7} \mathrm{BCG}$ bacilli, and their survival monitored for 8 weeks. Each group contained 10 mice. the growth of BCG in different tissues. Wild-type and TNF-deficient mice were infected with $10^{6}$ BCG bacilli intravenously and the number of colony-forming units (cfu) per organ was assessed over 8 weeks. Both wild-type and TNF-deficient mice showed a comparable increase in cfu counts in all organs analyzed up to 14 days after infection (Fig. 2a). However, 28 days after infection, wild-type mice controlled the infection, as demonstrated by a rapid decrease of cfu counts in liver and spleen, while the lungs showed some delay in eliminating the mycobacteria. In the absence of TNF, the clearance of mycobacteria was significantly delayed in liver and spleen $(p<0.05)$. Furthermore, mycobacterial growth was not controlled in the lungs of TNF-deficient mice $(p<0.01)$ as evident by the dramatic increase in the BCG cfu counts at day 56. This data confirms that TNF is essential for the control of mycobacterial growth, especially in the lung.

\section{LT Signaling Through TNF-R1 May Contribute to Mycobacterial Clearance}

The higher mortality rate of TNF-R1-deficient mice compared to TNF-deficient mice indicates that LT signaling through TNF-R1 may play a role in mycobacterial clearance. We examined this by comparing the mycobacterial loads in the lungs and spleens of TNF-deficient mice with the lungs and spleen of TNF/LT double-deficient mice after infection with $10^{6}$ BCG bacilli (Fig. 2b). We found significant differences in the mycobacterial loads of the lungs $(p<0.05) 28$ days after infection, and in the spleens $(p<0.01) 56$ days after infection. These differences may indicate that the inability of the TNF-deficient mice to clear a $B C G$ infection is further exacerbated by the absence of LT signaling through TNF-R1.

\section{Delayed Granuloma Formation in TNF-Deficient Mice}

It has been established that granulomas are crucial for mycobacterial clearance. Because TNF-deficient mice cannot efficiently clear BCG bacilli, we investigated the role of TNF in granuloma formation. We analyzed microscopic sections of liver and lungs from wild-type and TNF-deficient mice at 2, 4, and 8 weeks after BCG infection $\left(10^{6}\right.$ BCG bacilli injected intravenously). Typical granulomas were evident in the liver of wild-type mice 2 weeks after infection. These granulomas increased in size by 4 weeks and were comprised of activated macrophages resembling epitheloid cells and a darker lymphoid mantle zone. Eight weeks after infection, the granulomas became smaller and less abundant, indicating control of infection (Fig. 3a). In contrast, TNF-deficient mice developed small clusters of mononuclear cells 2 weeks after infection, whereas immature granulomas were detectable 4 weeks after infection. The mycobacterial loads in tissues were further assessed by Ziehl Neelsen staining for acid fast bacilli (AFB). Eight weeks after infection, the number of AFB in granulomas of wild-type livers were few (averaging approximately 1 to 3 AFB per granuloma), while more than 10 AFB per granuloma were present in liver 

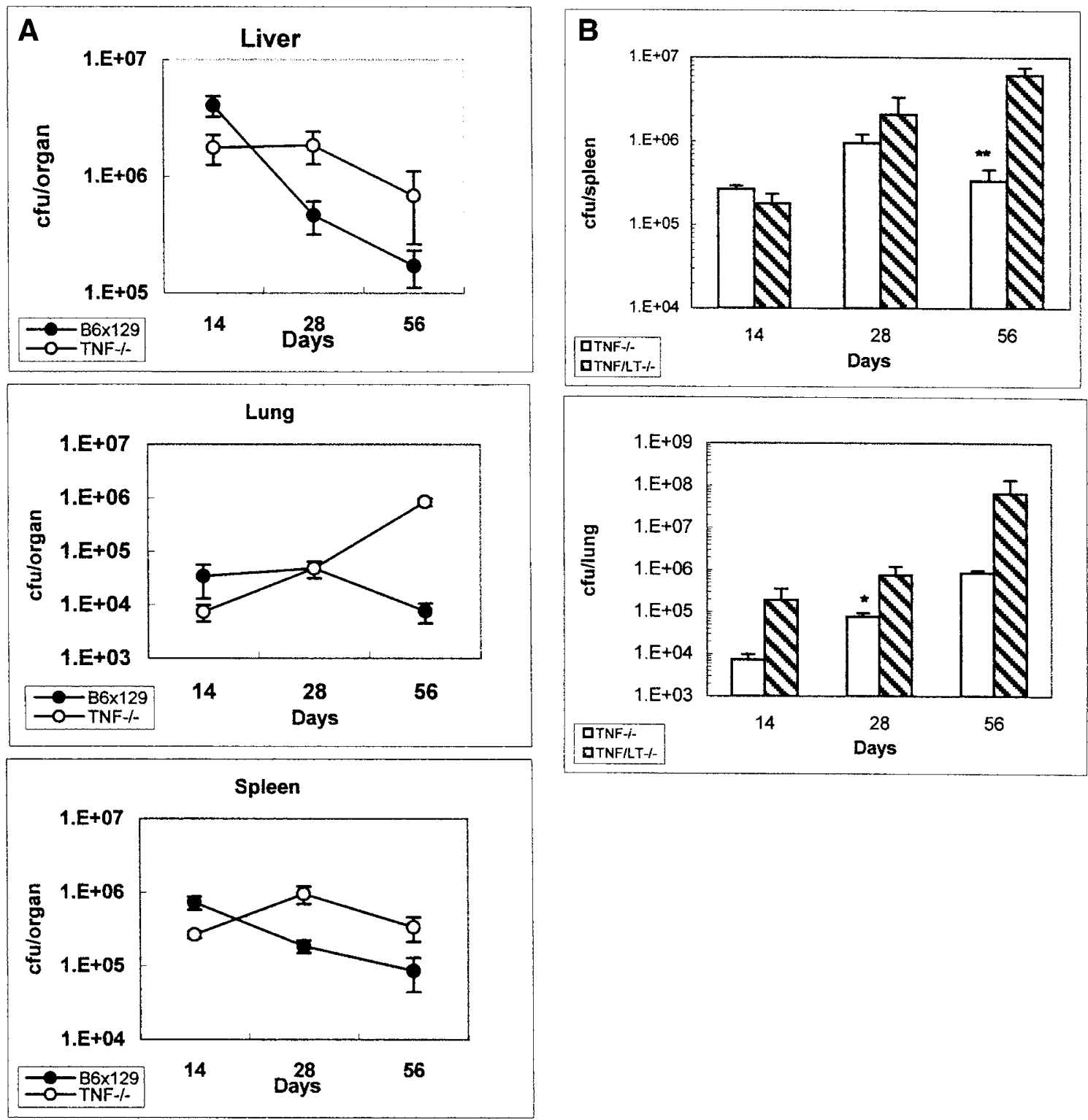

Figure 2.

A, Mycobacterial burden in organs of TNF-deficient mice infected with M. bovis BCG. The bacterial load in liver, lung, and spleen (cfu) was determined at 14, 28, and 56 days after BCG infection ( $10^{6} \mathrm{BCG}$ bacilli, intravenous) of TNF-deficient $(0)$ and wild-type $(\bullet)$ mice. The results are expressed as the mean \pm sD from four mice. The data are representative of three independent experiments. B, Mycobacterial burden in the spleen and lungs of TNF-deficient mice (open bars) and TNF/LT double-deficient mice (hatched bars). Mice were infected with M. bovis BCG (106 BCG bacilli, intravenous) and the number of cfu determined after 14, 28 , and 56 days. The results are expressed as the mean \pm SD of four mice. $\star p<0.05 ; \star \star p<0.01$

sections from TNF-deficient mice (Fig. 3b). The number of hepatic granulomas were assessed at 2, 4, and 8 weeks after infection (Fig. 4). Wild-type mice had maximum granuloma formation 2 weeks after infection, with a decline over the 8-week period. TNFdeficient mice displayed significant delays in granuloma formation and never reached wild-type levels.

In view of the dramatic increase in the mycobacterial load in the lung of TNF-deficient mice, the cellmediated response in the lungs was of particular interest. Wild-type mice displayed well-defined granulomas with noninfiltrated alveolar spaces at 8 weeks after infection. TNF-deficient mice had abundant mononuclear and polynuclear cell infiltrations obliter- ating most of the alveolar space and no defined granulomas (Fig. 5).

The disparity between wild type and TNF-deficient mice in their ability to control mycobacterial growth was further demonstrated by the detection of AFB in the lung. Few AFB were observed in well-defined granulomas in wild-type mice, uncontrolled growth of BCG was observed in the lungs of TNF-deficient mice (Fig. 5).

\section{Cellular Composition of Granulomas}

We investigated the cellular composition of the granulomas and asked whether the inflammatory response 
WT

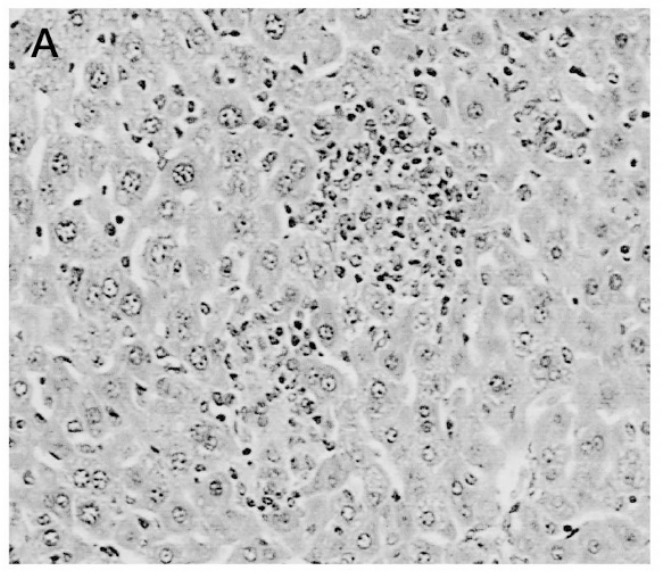

$\mathrm{D} 28$
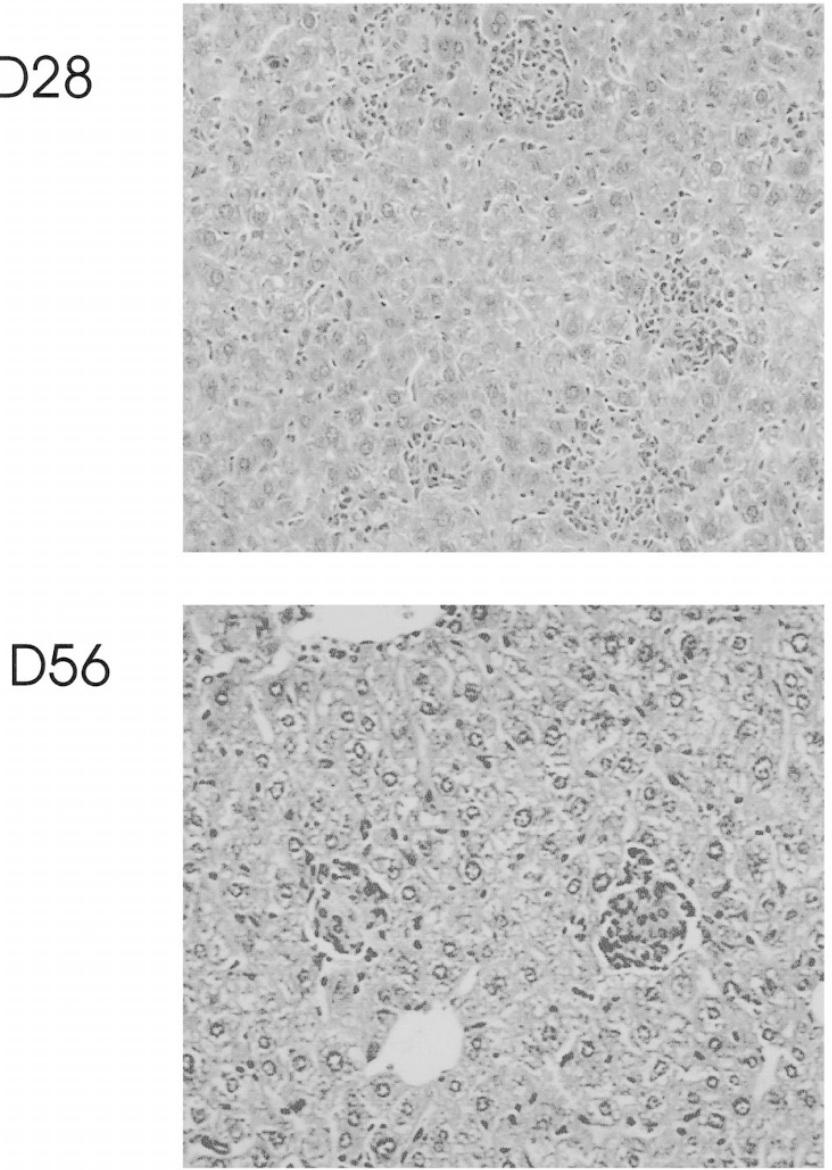

TNF KO
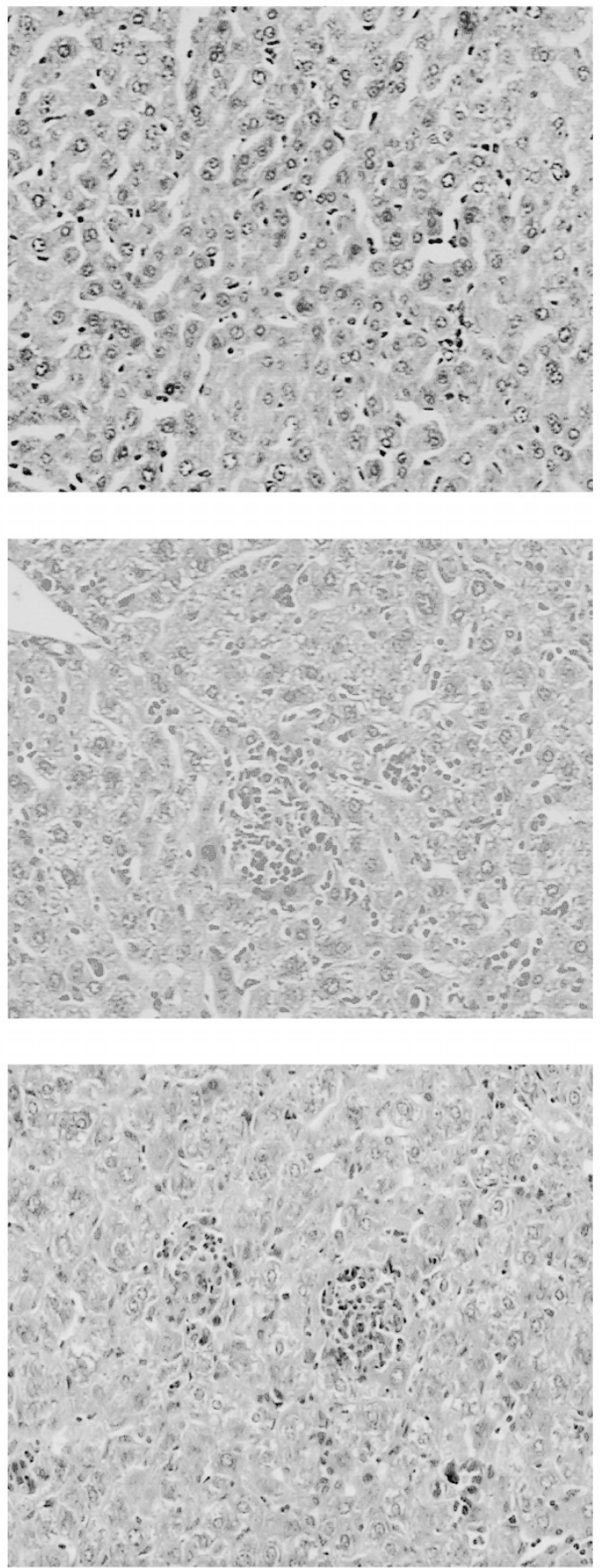

Figure 3A.

Representative hepatic granulomas from M. bovis BCG-infected wild-type and TNF-deficient mice. Mice were sacrificed 2, 4, and 8 weeks after infection and sections were stained with a: hematoxylin and eosin $(\times 400)$ or b: Ziehl Neelsen $(\times 1000) 4$ weeks after infection to detect AFB.

in the liver and lungs of BCG-infected wild-type and TNF-deficient mice was qualitatively comparable. Two weeks after intravenous infection with $10^{6} \mathrm{BCG}$ bacilli, distinct granulomas in the liver of wild-type mice contained CD3-positive $\mathrm{T}$ cells and $\mathrm{F} 4 / 80^{+}$macrophages expressing MHC class II and ICAM-1 (not shown). The granulomas increased in size during the next 2 weeks, with typical epitheloid cell differentia- tion, strong F4/80 and MHC class II expression, and CD3-positive $T$ cells in the periphery (Fig. 6a). Both CD4 and CD8 T cells were found in granulomas (not shown). Furthermore, there was a high expression of the adhesion molecules ICAM-1, CD11b and CD11c (Fig. 6b). By contrast, in TNF-deficient mice, a diffuse mononuclear cell infiltration of F4/80-positive cells predominated in the liver, with an insignificant granu- 


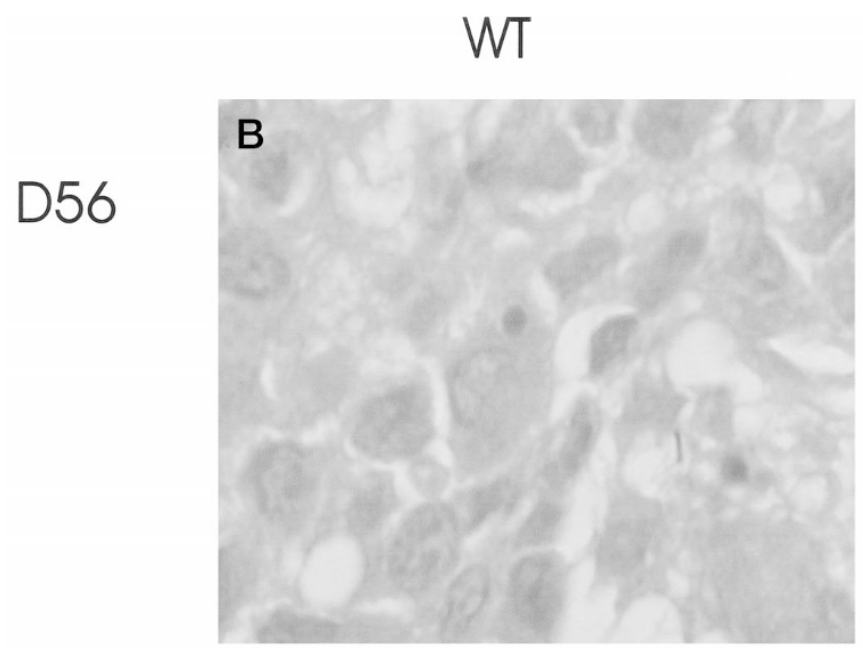

\section{TNF KO}

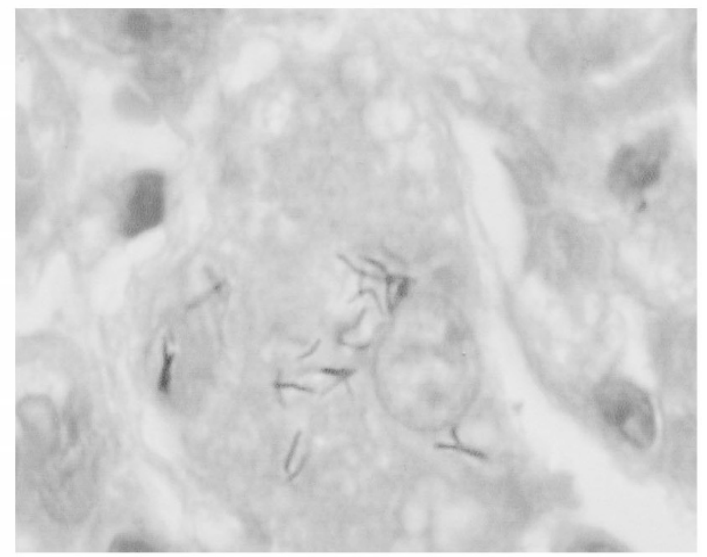

Figure 3B.

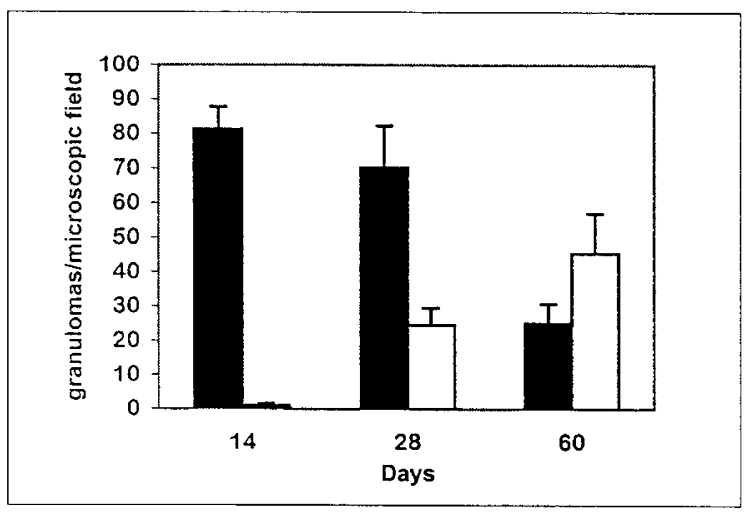

\section{Figure 4.}

Number of hepatic granulomas per microscopic field in TNF-deficient (open bars) and wild-type mice (closed bars) 14,28 , and 60 days after infection $\left(10^{6}\right.$ BCG bacilli, intravenous). Mononuclear cell clusters of more than 15 cells were counted as granulomas. The results are expressed as the mean \pm SD $(n=8$ mice).

lomatous reaction, low expression of $\mathrm{MHC}$ class II, and few $\mathrm{T}$ cells (Fig. 6a). The expression of ICAM-1 and CD11b was reduced, and CD11c expression was absent (Fig. 6b). This may reflect defective adhesive and phagocytic properties of the cells recruited to the infectious site. The expression of CD40 did not differ in the two groups (not shown).

The activation of the macrophages was clearly arrested in the absence of TNF. The intensity of F4/80 immunoreactivity was reduced, indicating low levels of macrophage differentiation (Gordon et al, 1992). Four weeks after infection, acid phosphatase (AP) activity and iNOS immunoreactivity in the liver were lower than levels in livers from wild-type control mice (Fig. 7a). AP activity (Fig. 7b) was quantified in splenic homogenate by enzyme assay and was significantly lower in TNFdeficient mice when compared with splenic homogenates from wild-type control mice $(p<0.05)$.

\section{Chemokine Production}

In view of the poor recruitment of inflammatory cells to sites of infection, we investigated whether chemokine production was reduced. We compared the chemokine levels in the broncho-alveolar lavage (BALF) of wild-type mice and TNF-deficient mice at 28 and 56 days after infection (Fig. 8). Because the chemokines MCP-1 and MIP-1 $\alpha$ were previously shown to mediate cellular recruitment, they were chosen for examination. We found no significant difference in MCP-1 levels in BALF of wild type and TNF-deficient mice 28 days after infection. However, 56 days after infection, MCP-1 levels were significantly higher in TNFdeficient mice when compared with wild-type mice $(p<0.05)$. We measured the production of MIP- $1 \alpha$ in BALF of TNF-deficient mice but were unable to detect this chemokine in BALF of wild-type mice under our assay conditions. This suggests that MCP-1 and MIP- $1 \alpha$ are produced independently from TNF and that the lack of inflammatory cells recruited to the sites of infection is a consequence of a reduced adhesion molecule expression rather than a chemokine deficiency.

\section{TNF-Deficient Mice Reconstituted with Wild-Type Bone Marrow}

To examine whether the impaired response of TNFdeficient mice to a BCG infection could be rectified by hemopoietic-derived TNF alone, we reconstituted irradiated TNF-deficient mice with wild-type bone marrow cells (TNF-WTBM) or TNF-deficient bone marrow cells (TNF-TNFBM). Wild-type mice were also reconstituted with wild-type bone marrow as a control (WT-WTBM). Four months after reconstitution, the mice were intravenously infected with $10^{7}$ BCG bacilli, and the bacterial load was assessed in liver, spleen, and lungs after 4 weeks. We previously demonstrated that wild-type bone marrow transplantation restored the release of TNF after lipopolysaccharide (LPS) injection of TNF/LT double-deficient mice (Muller et al, 1996). The data presented here demonstrate that TNF-WTBM mice were able to control mycobacterial growth to a similar extent as the wild-type controls (Fig. 9). The ability of the TNF-WTBM mice to control mycobacterial growth was further reflected in the 
WT
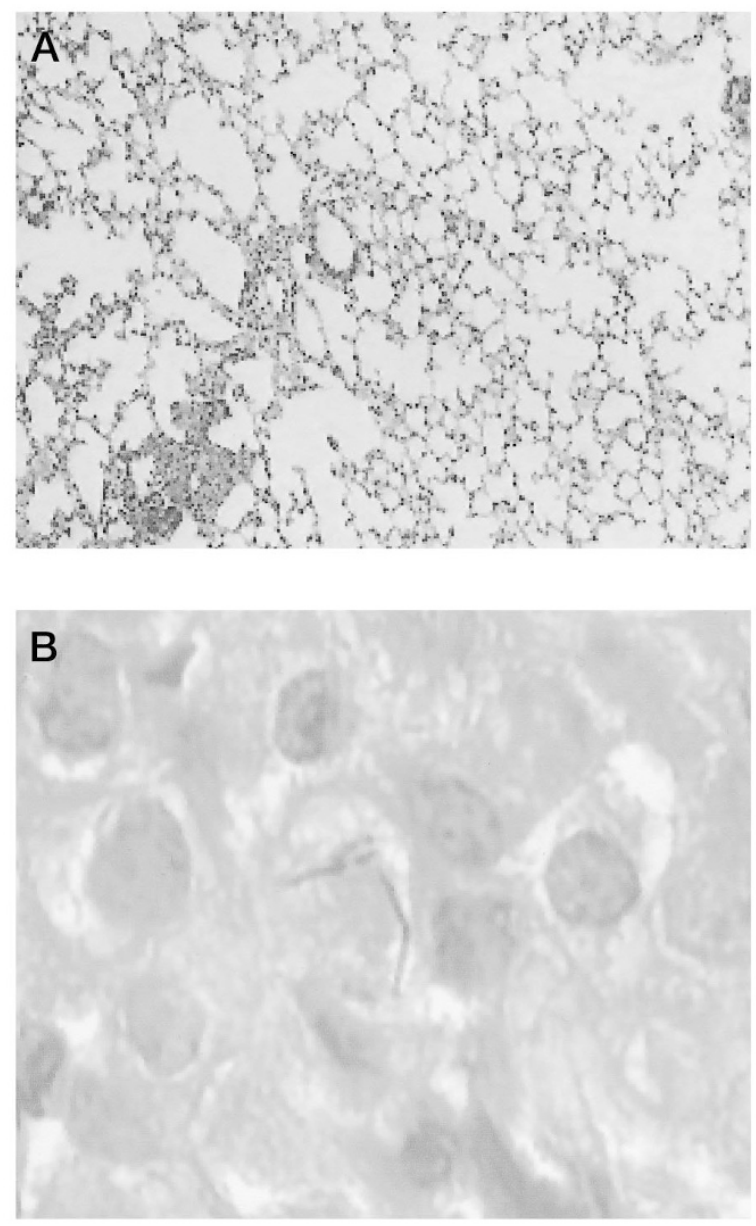

TNF KO
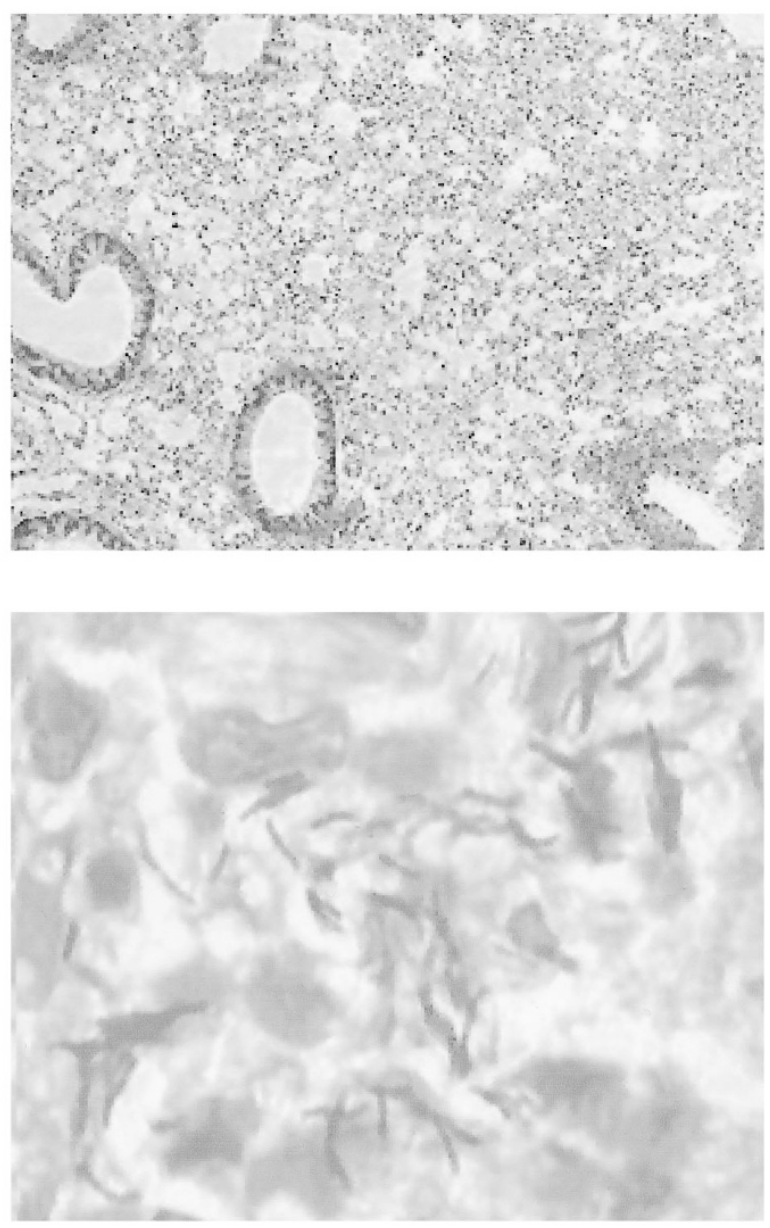

\section{Figure 5.}

Lung sections from $M$. bovis BCG infected wild-type and TNF-deficient mice 8 weeks after infection. Typical granulomas are seen in wild-type mice, while in TNF-deficient mice a diffuse, mixed inflammatory cell infiltrate prevailed, which obliterated the alveolar space. A, hematoxylin and eosin $(\times 100)$, B, Ziehl Neelsen $(\times 1000)$.

restoration of the granulomatous response (Fig. 10). TNF-WTBM mice survived the 3-month experiment, as did their wild-type littermates (not shown). Therefore, hematopoietic precursor cells are sufficient to restore resistance to mycobacterial infection.

\section{Discussion}

The data demonstrate that TNF is essential for the initial recruitment of mononuclear cells and subsequent formation of effective bactericidal granulomas in the early stages of an $M$. bovis BCG infection. The failure to express TNF retards the granulomatous response, resulting in a fatal pulmonary infection. TNF-R1-deficient and TNF-deficient mice succumb to $M$. bovis BCG infections, although the former seem more susceptible. This suggests that LT could play a protective role in the response to a BCG infection. We addressed this possibility by comparing the mycobacterial loads in the spleens and lungs of TNF-deficient and TNF/LT double-deficient mice after BCG infection. The higher susceptibility of TNF/LT double- deficient mice suggests that LT signaling through TNF-R1 contributes to mycobacterial clearance. However, abnormal splenic development in TNF/LT double-deficient mice could not be excluded as a contributory factor to the higher mycobacterial load. Evidence supporting a role for LT-signaling in mycobacterial clearance shows that membrane $\mathrm{LT} \alpha 1 / \beta 2$ signaling through $L T \beta R$ plays an important role in splenic granuloma formation, while the TNF receptor pathway is requisite in other tissues (Lucas et al, 1999). The absolute requirement for TNF in the control of $M$. bovis BCG infection is in contrast to previously published data (Flynn, et al, 1995). This difference could be ascribed to possible incomplete inhibition of TNF signaling by neutralizing antibodies, differences in infectious dose, strain differences of BCG, or differences in the genetic backgrounds of the mice.

The current data demonstrate that distinct differences exist between the pulmonary immune response and the hepatic and splenic immune responses. In the absence of TNF, mycobacterial growth in the liver and 


\section{WT}

\section{$\mathrm{F} 4 / 80$}

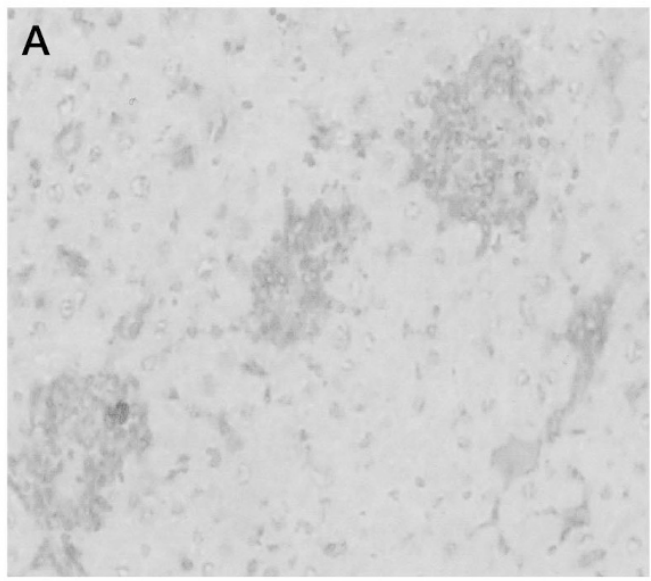

\section{CD3}

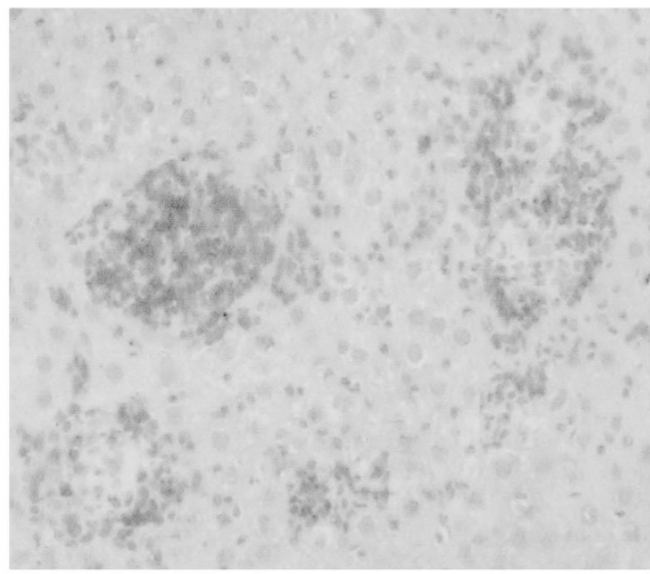

\section{Class II}

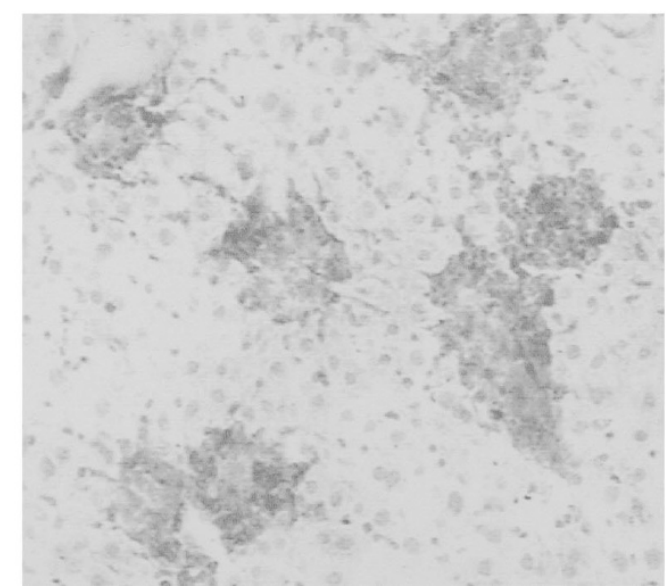

\section{TNF KO}
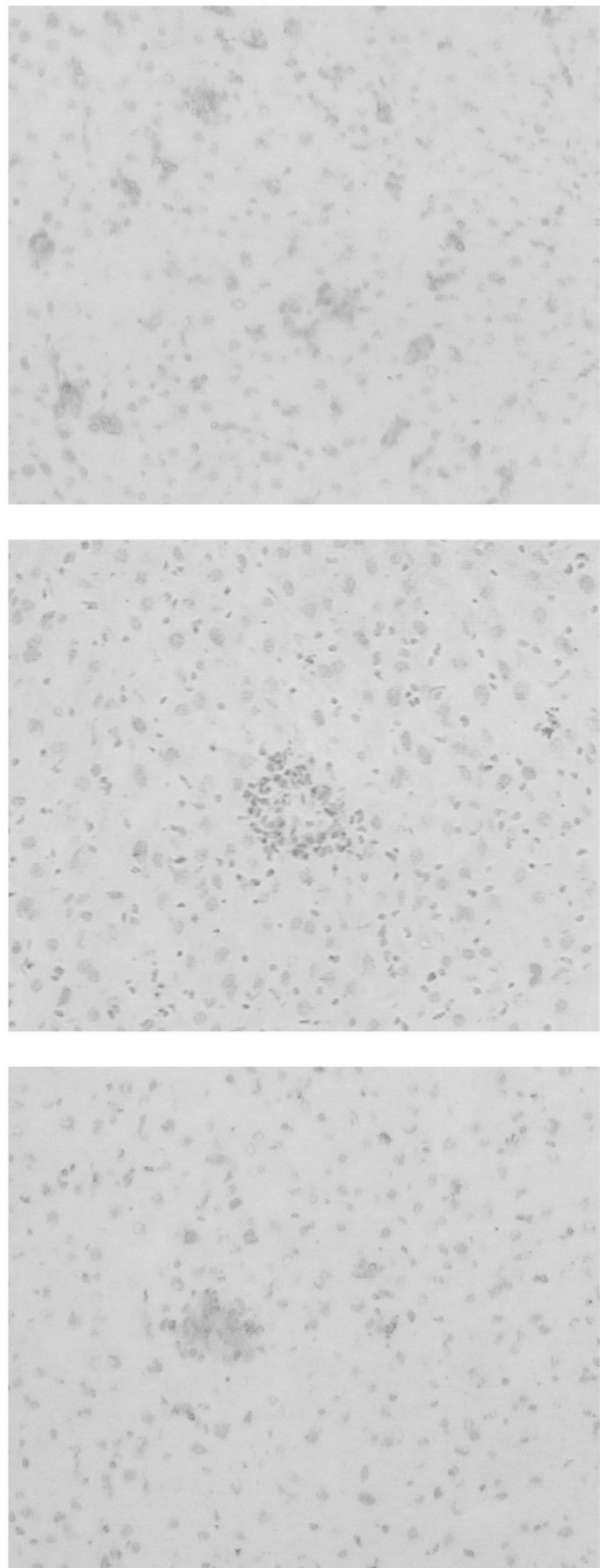

\section{Figure $6 \mathrm{~A}$.}

Cellular composition of hepatic granulomas in wild-type and TNF-deficient mice 4 weeks after infection. A, F4/80, CD3, MHC class II; and B, ICAM-1, CD11b, CD11c expression are clearly reduced in the TNF-deficient mice $(\times 400)$.

spleen is ultimately controlled, indicating TNF independent mechanisms, which were clearly absent in the lungs. As only a few $T$ cells are detected in the immature granulomas of TNF-deficient mice, it is assumed that local IFN $\gamma$ expression is reduced in the tissues.

It has been established that IFN $\gamma$ is essential to contain mycobacterial infection. In humans, IFN $\gamma$ re- ceptor deficiency leads to a predisposition to mycobacterial infections and impairs the formation of mature granuloma (Altare, et al, 1998; Jouanguy et al, 1996, 1997). In mice deficient in IFN $\gamma$ signaling, granuloma formation is reduced (Dalton et al, 1993; Flynn et al, 1993; Kamijo, et al, 1993a; 1993b). Because IFN $\gamma$ promotes TNF synthesis in murine macrophages (Beutler et al, 1986) and they act synergistically to 


\section{WT}

ICAM- 1
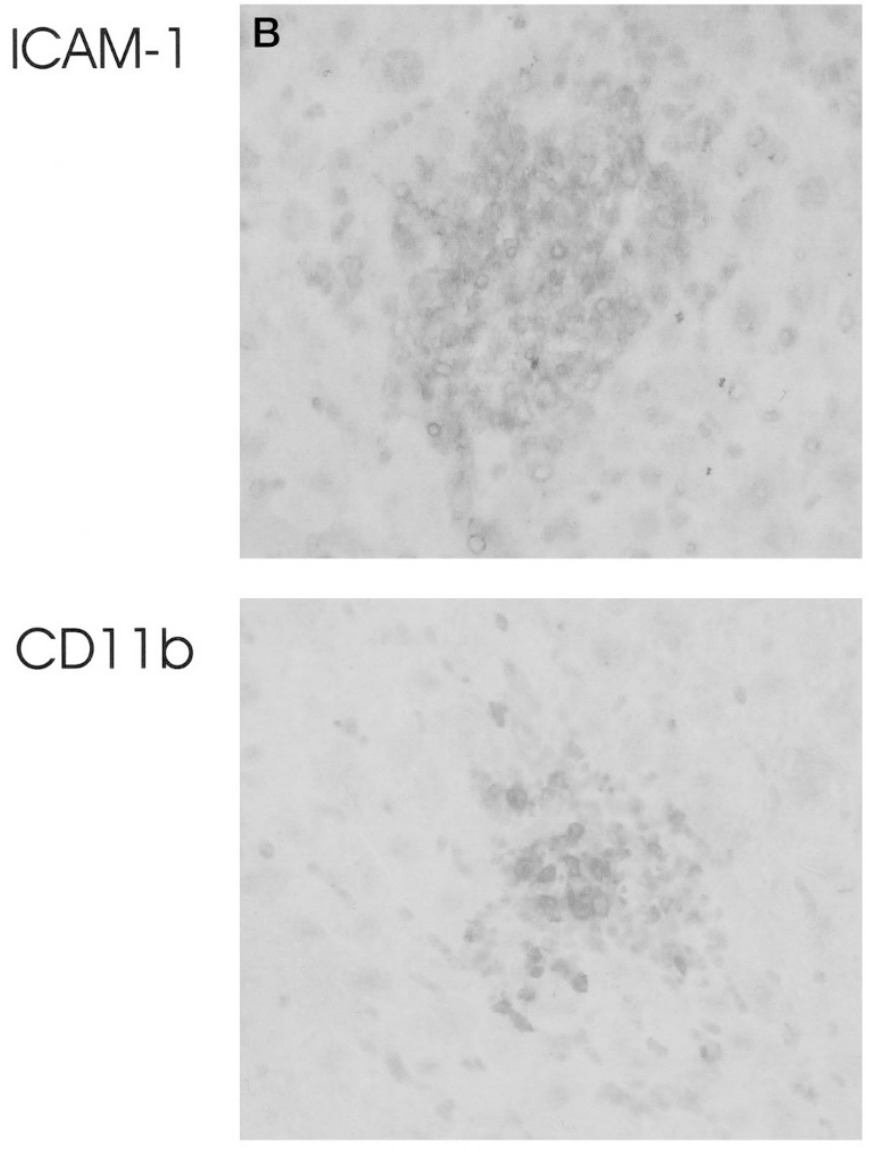

\section{CDI1C}

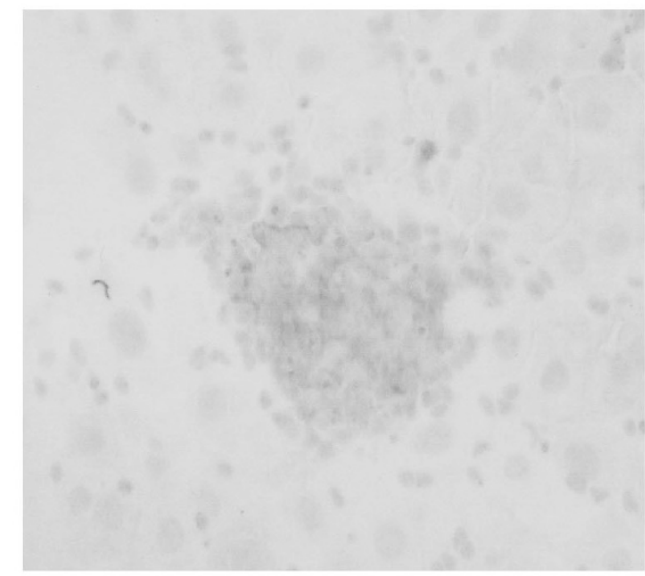

TNF KO
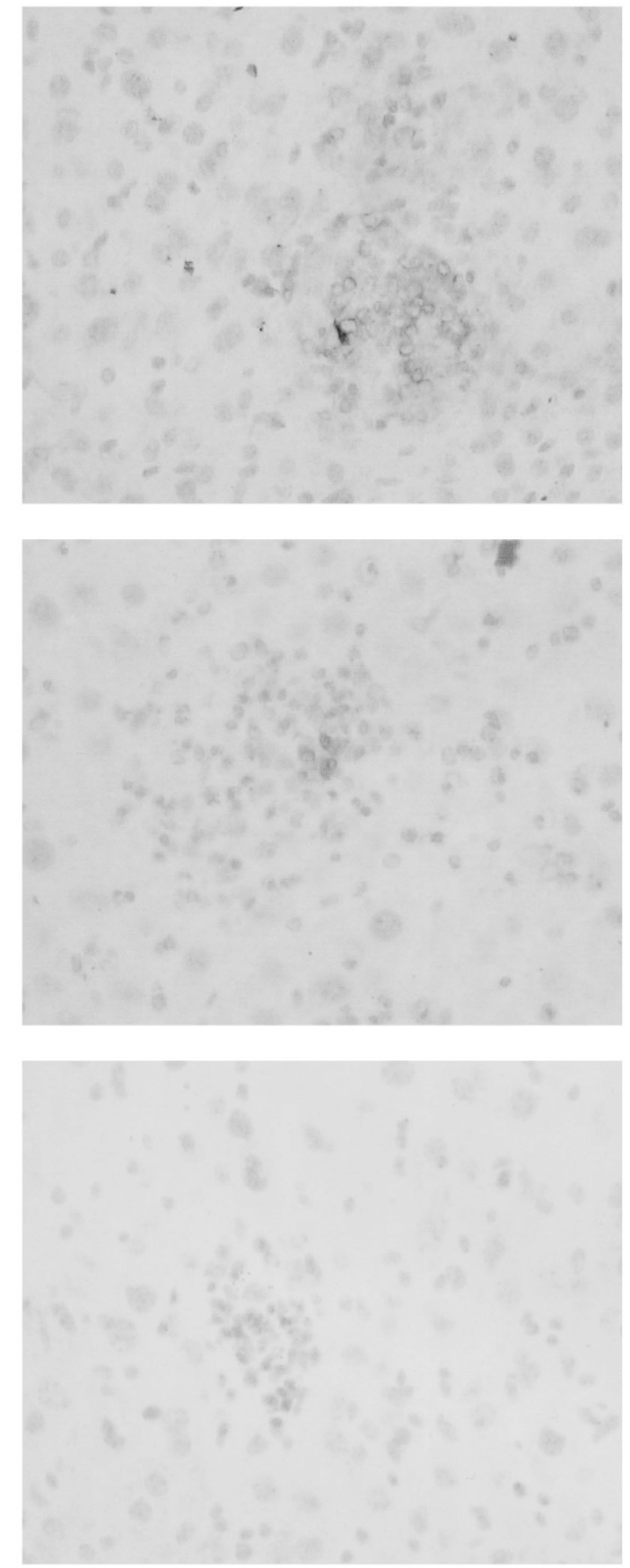

\section{Figure 6B.}

induce microbiocidal activity and nitric oxide release in macrophages (Chan et al, 1992; Kamijo et al, 1993a; 1993b), both IFN $\gamma$ and TNF are likely to be important in controlling mycobacterial infection and granuloma formation. We found reduced iNOS expression in hepatic and pulmonary granulomas of TNF-deficient mice compared with wild-type mice. In TNFR-1-deficient mice, Flynn et al demonstrated delayed iNOS expression in M. tuberculosis infected mice (Flynn, et al, 1995). Similarly, nitric oxide production was reduced in TNF-deficient mice (not shown) as reported for
IFN $\gamma$-deficient mice infected with mycobacteria (Dalton, et al, 1993; Kamijo, et al, 1993a; 1993b). The essential role of nitric oxide for host resistance has been elegantly demonstrated using nos2 deficient mice (MacMicking et al, 1997). Therefore both IFN $\gamma$ and TNF are required to fully activate iNOS. A key role of iNOS is further demonstrated in mice recovered from mycobacterial infection, because iNOS activity causes reactivation of latent disease (Flynn et al, 1998). Furthermore, infection could be reactivated by neutralization of TNF or IFN $\gamma$, which disrupt granulo- 
WT

Apase

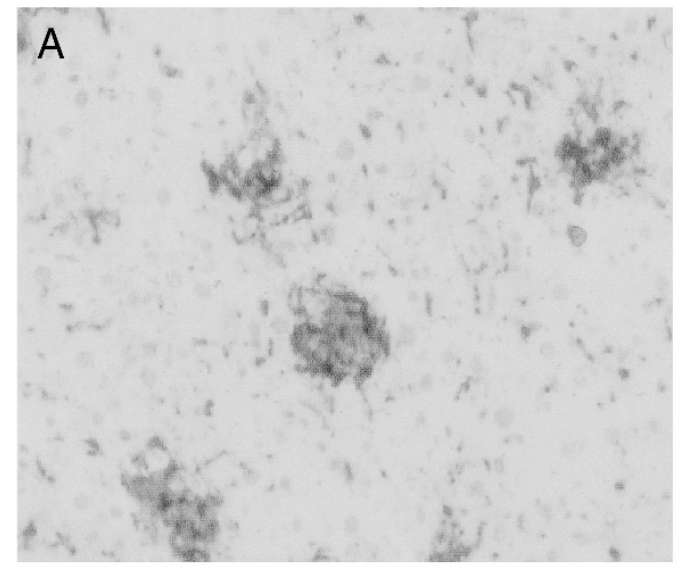

iNOS

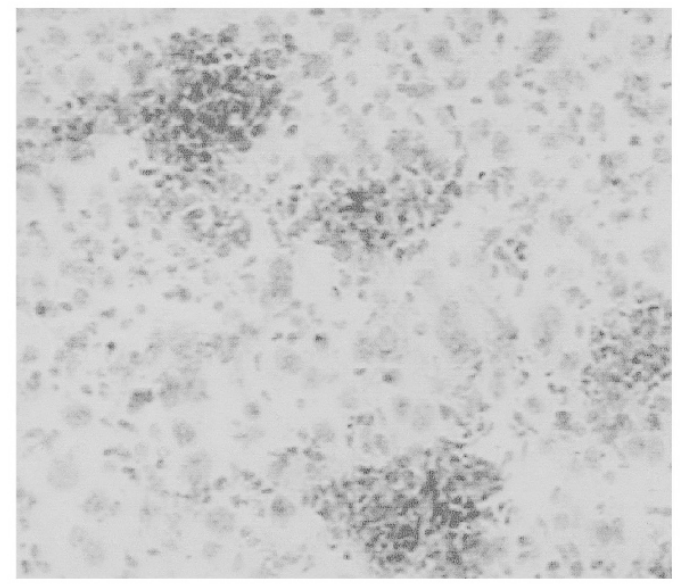

TNF KO
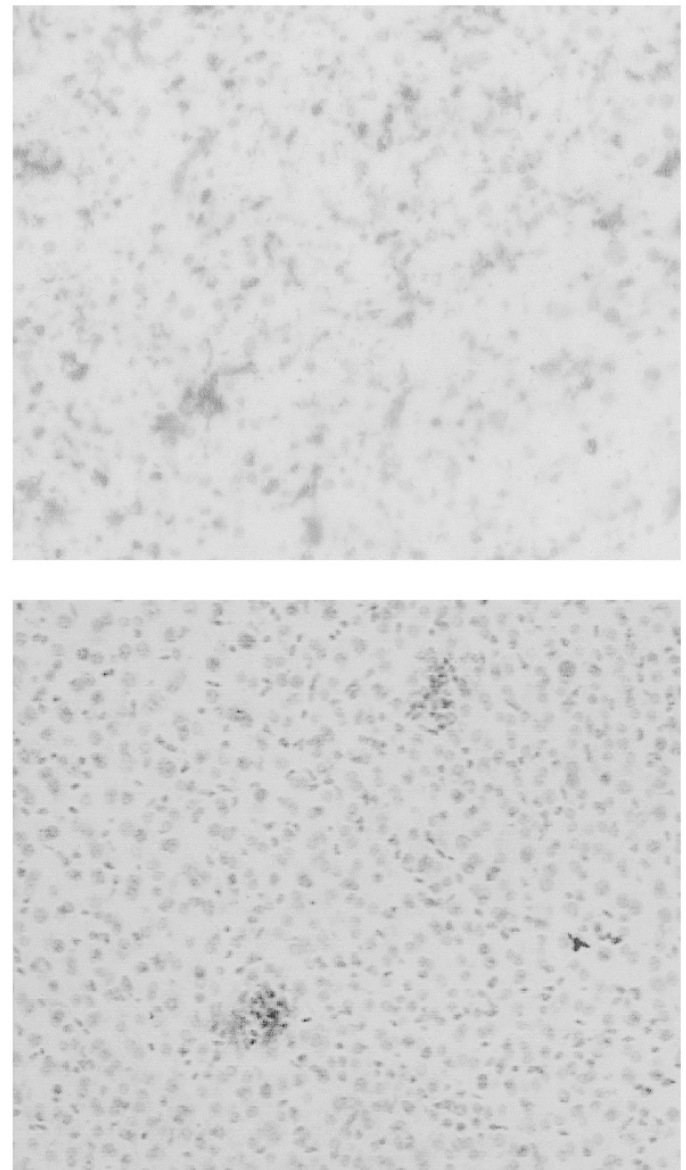

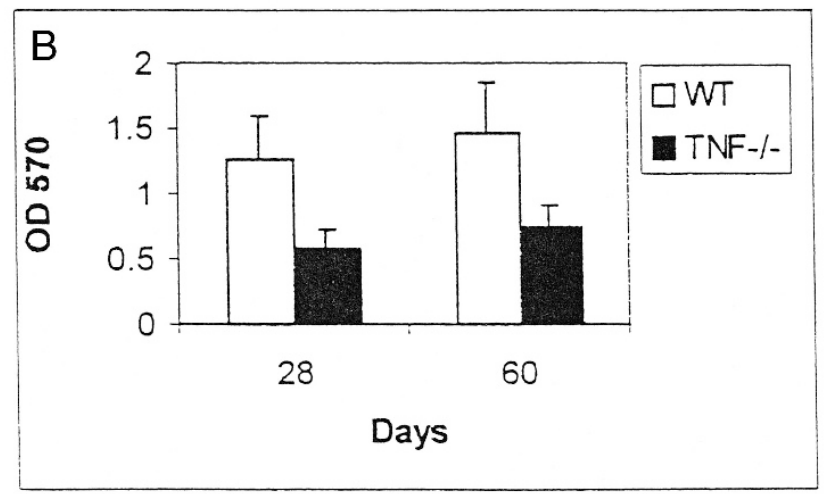

\section{Figure 7.}

Expression of acid phosphatase (AP) and iNOS in tissues of wild-type and TNF-deficient mice 4 weeks after infection with M. bovis BCG (106 bacilli, intravenous). A, AP enzymatic activity and iNOS immunoreactivity in frozen hepatic tissues of wild-type and TNF-deficient mice $(\times 400)$. B, AP enzymatic activity in splenic homogenates of wild-type (open bars) and TNF-deficient mice (closed bars), as described in Materials and Methods.

mas resulting in an increased mycobacterial load (Kindler, et al, 1989; Senaldi, et al, 1996; Smith et al, 1997).

Defective granuloma formation has recently been confirmed after $M$. tuberculosis aerosol infection in TNF-deficient mice (unpublished data and Bean et al, 1999). TNF-deficient mice succumb to $M$. tuberculosis infection within 4 to 5 weeks with pneumonia, despite normal recruitment of mononuclear cells into the lung, normal cytokine responses, and activation of macrophages (Bean, et al, 1999). As residual granuloma like structures were ultimately formed in TNF-deficient mice, other factors may play a compensatory role in recruiting mononuclear cells to the site of infection. Alternative mechanisms of mononuclear cell recruitment in TNF-deficient mice might include IFN $\gamma, \mathrm{IL}-12$, or LT; eg, through upregulation of adhesion molecules and induction of chemokines. We found increased 

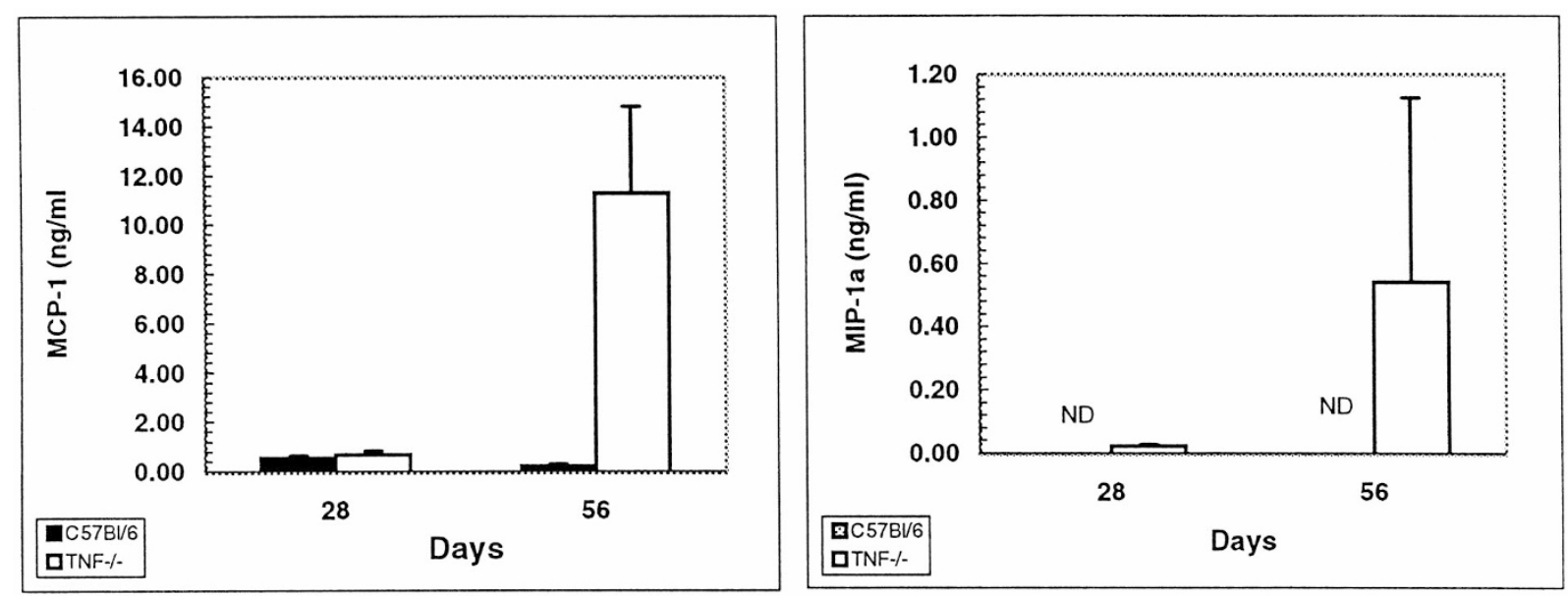

\section{Figure 8}

Chemokine secretion from wild-type and TNF-deficient mice, 28 and 56 days after infection. MCP-1 and MIP-1 $\alpha$ production in brocho-alveolar lavage fluid from wild-type (closed bars) and TNF-deficient mice (open bars) after M. bovis BCG infection. The results are expressed as the mean $\pm \mathrm{SD}(n=4)$.

IL-12 serum levels which correlate with the increased bacterial load, indicating that TNF-deficient mice are able to produce IL-12. TNF serum levels were only detectable in the low $\mathrm{pg} / \mathrm{ml}$ range in wild-type mice, and IFN $\gamma$ levels were undetectable.

The reduction of ICAM-1 expression in TNFdeficient mice may have functional significance because the formation of mycobactericidal granuloma was shown to be ICAM-1 dependent (Johnson et al, 1998). ICAM-1-deficient mice were able to raise partial protective immunity in response to $M$. tuberculosis infection despite the absence of granulomas, but succumbed to chronic infection.

We show here, for the first time, reduced expression and/or recruitment of CD11b-positive cells. Furthermore, we demonstrate that the expression of CD11c, a $\beta 2$ integrin, is upregulated in differentiated granulomas in wild-type mice. Interestingly, CD11c upregulation is strictly TNF-dependent. To our knowledge, upregulation of CD11b and CD11c has only been reported on peripheral blood leukocytes of patients affected with tuberculosis (Yassin and Hamblin, 1994). Our data suggest that TNF is essential for the upregulation of CD11b and CD11c expression in response to a BCG infection. The implications of reduced ICAM-1 and CD11c expression in TNF-deficient mice may be impaired adherence to endothelium and recruitment of inflammatory cells. The reduced CD11b expression may further contribute to the poor recruitment of cells and impaired phagocytosis of mycobacteria (Coxon et al, 1996).

There is experimental evidence demonstrating that chemokines are induced in mycobacterial infection (Rhoades et al, 1995). Using chemokine receptordeficient mice, signaling through chemokine receptor (CCR2) and CCR5 was shown to be essential for granulomatous tissue reactions (Boring et al, 1997; Kurihara et al, 1997; Zhou et al, 1998). Our data provide evidence for TNF-independent production of both MCP-1 and MIP-1 $\alpha$ in vivo. Previously, Lin et al showed that MCP-1 production can be stimulated in a human alveolar epithelial cell line in response to $M$. tuberculosis infection, independent of TNF (Lin et al, 1998 ). Therefore, the inability of TNF-deficient mice to recruit cells to sites of infection and the subsequent bacterial clearance are not due to the reduction of MCP- 1 or MIP- $1 \alpha$. The dramatically increased chemokine response observed in the TNF-deficient mice might be a consequence of the frustrated attempt to recruit effector cells to control the expanding BCG infection. Lu et al have shown that MCP-1, the primary ligand for CCR2, had, however, no effect on the clearance of $M$. tuberculosis from the infected host ( $\mathrm{Lu}$ et al, 1998).

In conclusion, we demonstrated that TNF is essential for the expression of adhesion molecules such as CD11b, CD11c, and ICAM-1. The impaired recruitment and activation of phagocytes and T-cells resulted in a fatal infection with $M$. bovis BCG. Finally, the defective response to an $M$. bovis BCG infection in TNF-deficient mice could be corrected after transplantation with wild-type bone marrow. This data suggests that TNF produced by bone marrow-derived effector cells is sufficient to correct the defective mycobacterial response in these mice.

\section{Materials and Methods}

\section{Animals}

Adult, 8 to 10 week old female homozygous TNF-R1 -/- and TNF -/- mice on a C57BL/6 genetic background (Drs. M. Marino, Ludwig Institute, New York, and $H$. Bluethmann, Hoffmann-La Roche, Basel) (Marino, et al, 1997; Rothe et al, 1993) and wild-type C57BL/6 mice were kept under specific pathogen conditions. The genotypes of the mouse populations were confirmed by PCR analysis of tail biopsies.

\section{Antibodies}

The following rat anti-mouse monoclonal antibodies were used for immunohistochemical detection: 

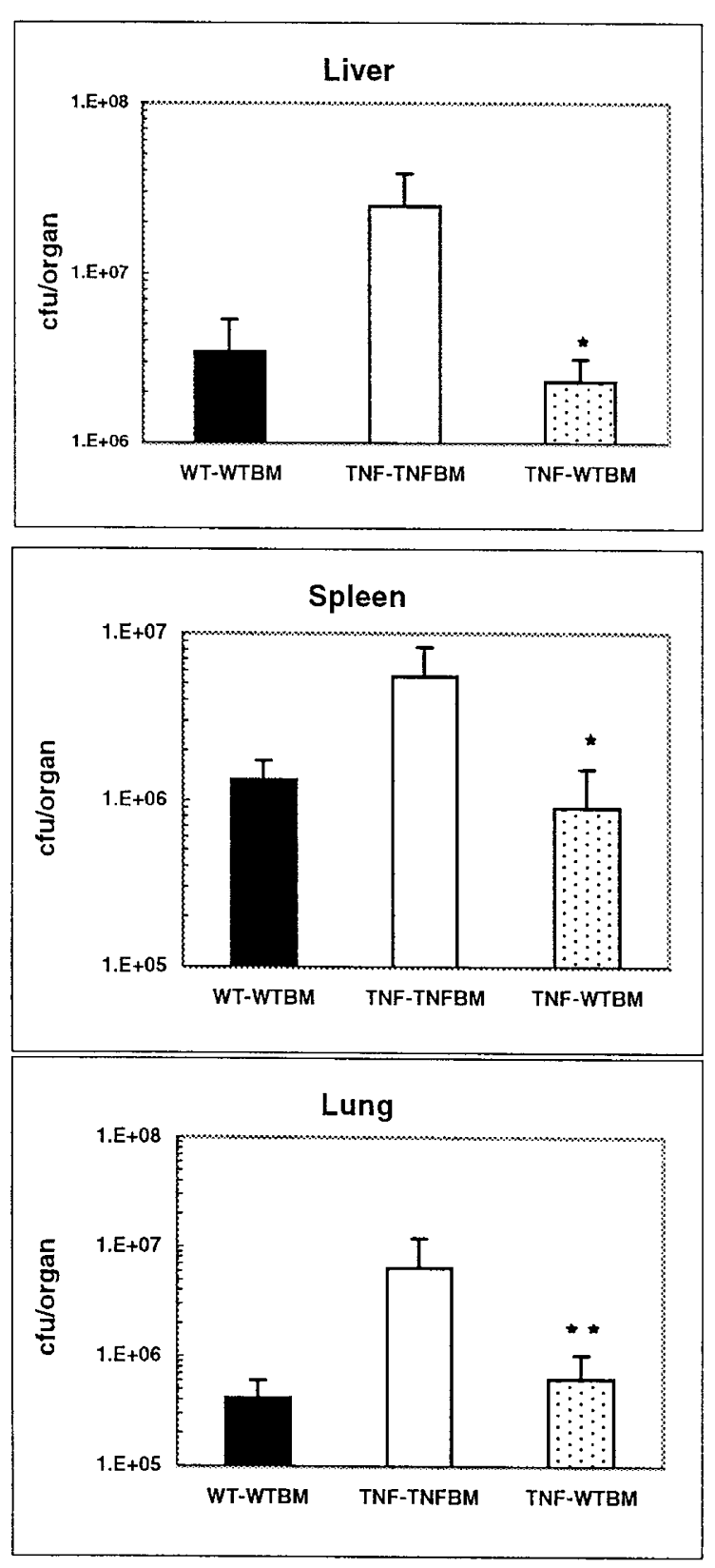

\section{Figure 9.}

Correction of host resistance to $M$. bovis BCG in TNF-deficient mice reconstituted with wild-type bone marrow. TNF-deficient and wild-type mice were lethally irradiated (10 Gy) and reconstituted with $2 \times 10^{6}$ bone marrow cells. TNF-deficient mice received either wild-type bone marrow (TNF-WTBM, dotted bars) or TNF-deficient bone marrow (TNF-TNFBM, open bars). Wild-type mice received wild-type bone marrow (WT-WTBM, closed bars) as a control. All mice were infected with $M$. bovis BCG 4 months later. The bacterial load in organs (cfu) was determined at 4 weeks after infection $\left(10^{6}\right.$ BCG bacilli, intravenous) in liver, lung, and spleen. The results are expressed as the mean $\pm \mathrm{SD}(n=4)$. $[\star] p<0.01 ;[\star][\star \star] p<0.05$.

ICAM-1 (clone YN1/1.7.4), F4/80 (clone HB0.198), MHC class II antigen (I-Ab, d,q, M5/114.15.2), MHC class I antigen (M1/42), CD3, CD4, CD8, CD11b, and CD11c (Pharmingen, San Diego, California). A rabbit polyclonal antibody to iNOS, obtained from Prof. J. Pfeilschifter, Frankfurt, Germany, was also used.

\section{Experimental Design}

Wild-type, TNF-R1-deficient, and TNF-deficient mice were each injected intravenously with infective doses of $10^{6}$ and $10^{7}$ BCG bacilli. Each group contained 16 mice and each experiment was repeated twice. At 1 day, 2 weeks, 4 weeks, and 8 weeks after infection, blood was taken by cardiac puncture and the mice were killed. The lung, liver, and spleen were weighed. The organs were either fixed in $4 \%$ buffered formalin or frozen on dry ice and maintained at $-80^{\circ} \mathrm{C}$. Five $\mu \mathrm{m}$-thick sections of the spleen, liver, and lungs were cut and stained for either hematoxylin and eosin or Ziehl Neelsen for AFB. Granulomas were quantified by counting in 100X high-power microscopic views. Clusters of more than 15 mononuclear cells forming a nodule were counted as a granuloma.

\section{Immunohistochemistry}

The frozen tissues (liver, spleen, and lungs) were cut at $6 \mu \mathrm{m}$ thickness on a cryostat and air-dried for storage at $-80^{\circ} \mathrm{C}$. Fixation in acetone $\left(10\right.$ minutes at $\left.4^{\circ} \mathrm{C}\right)$ was performed just before immunolabelling. After a rinse in PBS, the sections were incubated for 16 hours at $4^{\circ} \mathrm{C}$ with a primary antibody diluted in PBS. The sections were then washed in PBS and incubated for 30 minutes at room temperature with the rabbit antirat serum $A B C$ system (Vector Laboratories, Burlingame, California), followed by DAB substrate. After rinses in PBS, the sections were mounted in Immunomount (Shandon, Pittsburgh, Pennsylvania).

\section{Cfu}

Bacterial loads in the lung, liver, and spleen of infected mice were evaluated at 1 day, 2 weeks, 4 weeks, and 8 weeks after infection. Organs were weighed, and defined aliquots were homogenized in saline containing $0.04 \%$ Tween 80 . Ten-fold serial dilutions of organ homogenates were plated in duplicates onto Middlebrook 7H10 agar plates containing 10\% OADC (Difco, Detroit, Michigan). Plates were incubated at $37^{\circ} \mathrm{C}$ for 19 to 21 days and colonies were counted. Data were expressed as mean cfu per organ $(n=4)$.

\section{Bone Marrow Transplantation}

Recipient mice received a lethal total-body irradiation (using a 60 Cobalt source, $10 \mathrm{~Gy}$ ) prior to the intravenous injection of $2 \times 10^{6}$ fresh, unseparated bone marrow cells as described (Muller, et al, 1996). The mice were left to fully reconstitute and recover for at least 4 months before being infected with BCG.

\section{Detection of AP in Tissues}

AP on frozen tissue sections was performed as reported previously (Kindler, et al, 1989). In order to quantify the enzymatic activity, fresh livers and spleens $(250 \mathrm{mg}$ ) were homogenized in $1 \mathrm{ml}$ of $25 \mathrm{~mm}$ Tris- $\mathrm{HCl}(\mathrm{pH} 7.4), 10 \mathrm{~mm}$ EDTA. AP activity was assessed in supernatants of the homogenates 
WT-TNFBM
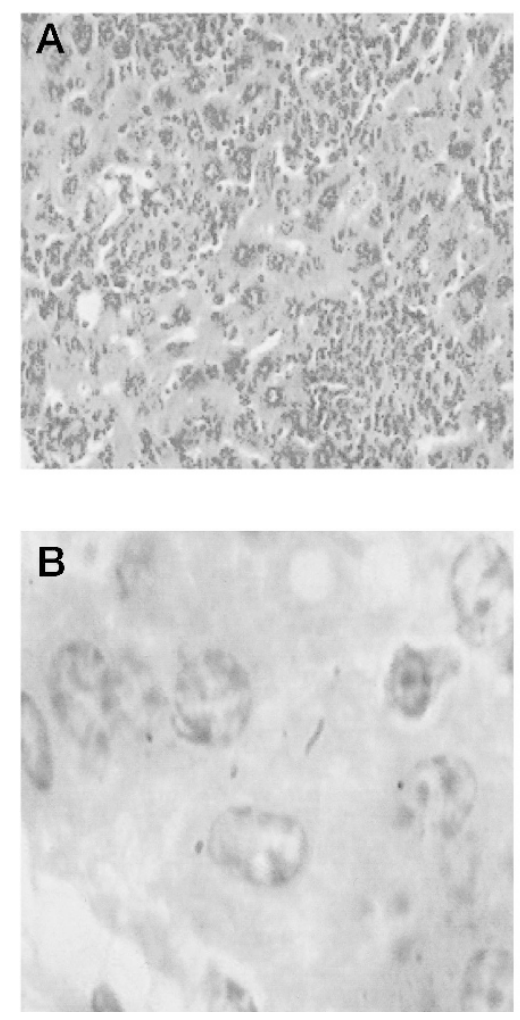

TNF-TNFBM
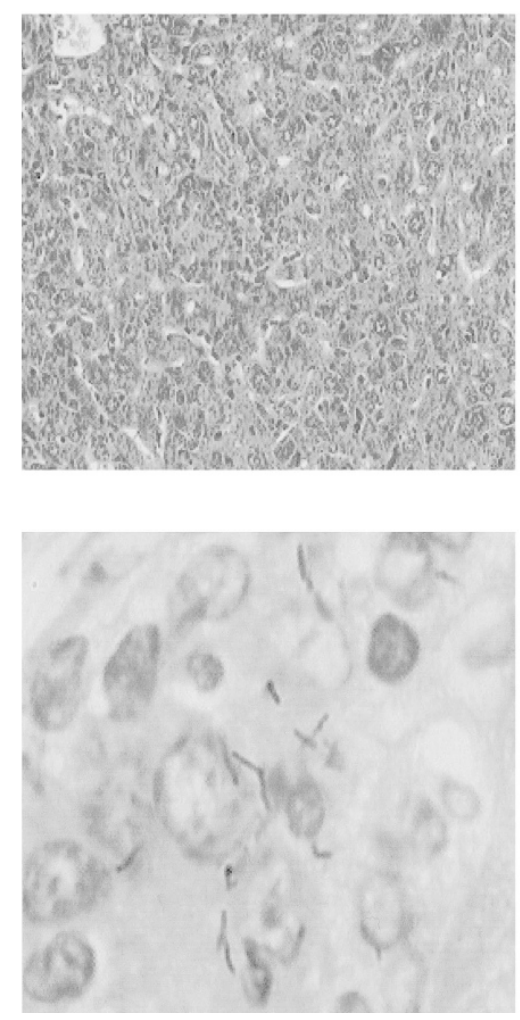

WT-WTBM
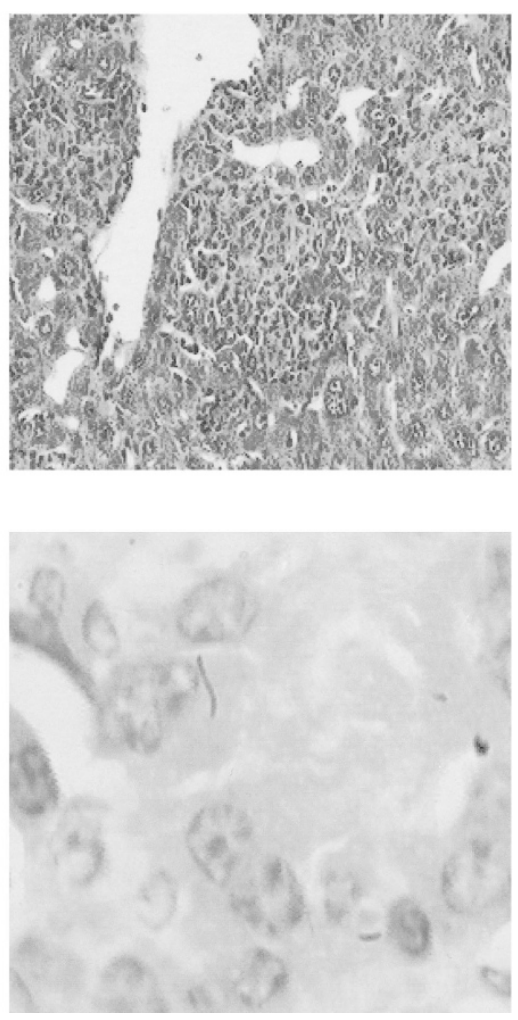

Figure 10.

Recovery of a granulomatous response to $M$. bovis BCG in TNF-deficient mice reconstituted with wild-type bone marrow. Typical granulomas were formed in TNF-WTBM as in the wild-type controls (WT-WTBM). The TNF-TNFBM reconstituted mice served as a negative control and were unable to form granuloma nor eliminate mycobacteria. A: hematoxylin and eosin $(\times 400)$ and B: Ziehl Neelsen $(\times 1000)$.

$(10,000 \times \mathrm{g}, 15$ minutes) by using sodium nitrite in naphtol-phosphate as substrate, and the reaction was measured after 20 minutes at room temperature at OD570 nm (Barka and Anderson, 1962).

\section{Bronch-Alveolar Lavage}

Control and BCG-infected mice were anaesthetized with a ketamine and xylazine mixture and a plastic 20 gauge cannula was inserted into the trachea. The lungs were lavaged with $0.5 \mathrm{ml}$ of sterile PBS with 0.5 mM EDTA. The BALF supernatant was frozen at $-80^{\circ} \mathrm{C}$ for detection of chemokines by ELISA.

\section{ELISA Assays for Chemokines}

MCP- 1 and MIP- $1 \alpha$ supernatants of BALF were measured by ELISA with a sensitivity of $<15 \mathrm{pg} / \mathrm{ml}$ (Pharmingen; and R\&D Systems, Abingdon, United Kingdom).

\section{Statistical Analysis}

Statistical evaluation of differences between the experimental groups was determined by the use of the Mann-Whitney $U$ test and the Student's t-tests.

\section{References}

Altare F, Durandy A, Lammas D, Emile JF, Lamhamedi S, Le $D F$, Drysdale $P$, Jouanguy $E$, Doffinger R, Bernaudin $F$, Jeppsson O, Gollob JA, Meinl E, Segal AW, Fischer A, Kumararatne D, and Casanova JL (1998). Impairment of mycobacterial immunity in human interleukin-12 receptor deficiency. Science 280:1432-1435.

Banks TA, Rouse BT, Kerley MK, Blair PJ, Godfrey VL, Kuklin NK, Bouley DM, Thomas J, Kanangat S, and Mucenski ML (1995). Lymphotoxin-a deficient mice. J Immunol 155:16851693.

Barka T and Anderson PJ (1962). Histochemical methods for acid phosphatase using hexazonium pararosanilin as coupler. J Histochem Cytochem 10:741-748.

Bean AG, Roach DR, Briscoe H, France MP, Kroner H, Sedgwick JD, and Britton WJ (1999). Structural deficiencies in granuloma formation in TNF gene-targeted mice underlie the heightened susceptibility to aerosol Mycobacterium tuberculosis infection, which is not compensated for lymphotoxin. J Immunol 162:3504-3511.

Beutler B, Tkacenko V, Milsark I, Krochin N, and Cerami A (1986). Effect of gamma interferon on cachectin expression by mononuclear phagocytes. J Exp Med 164:1791-1796.

Bloom BR (1994). Tuberculosis. In: Bloom BR, editor. Tuberculosis: Pathogenesis, protection and control. Washington, DC: ASM Press, p. 389-503. 
Boring L, Gosling J, Chensue SW, Kunkel SL, Farese RVJ, Broxmeyer HE, and Charo IF (1997). Impaired monocyte migration and reduced type 1 Th1 cytokine responses in C-C chemokine receptor 2 knockout mice. J Clin Invest 100: 2552-2561.

Chan J, Xing Y, Magliozzo RS, and Bloom BR (1992). Killing of virulent Mycobacterium tuberculosis by reactive nitrogen intermediates produced by activated murine macrophages. $J$ Exp Med 175:1111-1116.

Cooper AM, Dalton DK, Stewart TA, Griffin JP, Russell DG, and Orme IM (1993). Disseminated tuberculosis in interferon gamma gene-disrupted mice. J Exp Med 178:2243-2247.

Cooper AM, Magram J, Ferrante J, and Orme IM (1997). Interleukin 12 is crucial to the development of protective immunity in mice intravenously infected with Mycobacterium tuberculosis. J Exp Med 186:39-45.

Cooper AM, Roberts AD, Rhoades ER, Callahan JE, Getzy DM, and Orme IM (1995). The role of interleukin-12 in acquired immunity to Mycobacterium tuberculosis infection. J Immunol 84:423-432.

Coxon A, Rieu P, Barkalow FJ, Askari S, Sharpe AH, von Andrian UH, Arnaout MA, and Mayadas TN (1996). A novel role for the beta 2 integrin CD11b/CD18 in neutrophil apoptosis: A homeostatic mechanism in inflammation. Immunity 5:653-666.

Dalton DK, Pitts-Meek S, Keshav S, Figari IS, Bradley A, and Stewart TA (1993). Multiple defects of immune cell function in mice with disrupted interferon-gamma genes. Science 259: 1739-1742.

de Jong R, Altare F, Haagen IA, Elferink DG, Boer T, van Breda Vriesman PJ, Kabel PJ, Draaisma JM, van Dissel JT, Kroon FP, Casanova JL, and Ottenhoff TH (1998). Severe mycobacterial and Salmonella infections in interleukin-12 receptor-deficient patients. Science 280:1435-1438.

De Togni P, Goellner J, Ruddle NH, Streeter PR, Fick A, Mariathasan S, Smith SC, Carlson R, Shornick LP, StraussSchoenberger J, Russel JH, Karr R, and Chaplin DD (1994). Abnormal development of peripheral lymphoid organs in mice deficient in lymphotoxin. Science 264:703-707.

Eugster HP, Muller M, Karrer U, Car BD, Schnyder B, Eng VM, Woerly G, Le Hir M, Di Padova F, Aguet M, Zinkernagel R, Bluethmann $H$, and Ryffel B (1996). Multiple immune abnormalities in tumor necrosis factor and lymphotoxina double-deficient mice. Int Immunol 8:23-36.

Flynn JL, Chan J, Triebold KJ, Dalton DK, Stewart TA, and Bloom BR (1993). An essential role for interferon gamma in resistance to Mycobacterium tuberculosis infection. J Exp Med 178:2249-2254.

Flynn JL, Goldstein MM, Chan J, Triebold KJ, and Bloom BR (1995). Tumor necrosis factor-alpha is required in the protective immune response against mycobacterium tuberculosis in mice. Immunity 2:561-572.

Flynn JL, Scanga CL, Tanaka KE, and Chan J (1998). Effects of aminoguanidine on latent murine tuberculosis. J Immunol 160:1796-11803.

Gordon S, Lawson L, Rabinowitz S, Crocker PR, Morris L, and Perry VH (1992). Antigen markers of macrophage differentiation in murine tissues. Curr Topics Microbol Immunol 181:1-37.

Johnson CM, Cooper AM, Frank AA, and Orme IM (1998). Adequate expression of protective immunity in the absence of granuloma formation in Mycobacterium tuberculosisinfected mice with a disruption in the intracellular adhesion molecule-1 gene. Infect and Immun 66:1666-1670.

Jouanguy E, Altare F, Lamhamedi S, Revy P, Emile JF, Newport M, Levin M, Blanche S, Seboun E, Fischer A, and Casanova JL (1996). Interferon-gamma-receptor deficiency in an infant with fatal bacille Calmette-Guerin infection. N Engl J Med 335:1956-1961.

Jouanguy E, Lamhamedi CS, Altare F, Fondaneche MC, Tuerlinckx D, Blanche S, Emile JF, Gaillard JL, Schreiber R, Levin M, Fischer A, Hivroz C, and Casanova JL (1997). Partial interferon-gamma receptor 1 deficiency in a child with tuberculoid bacillus Calmette-Guerin infection and a sibling with clinical tuberculosis. J Clin Invest 100:2658-2664.

Kamijo R, Le J, Shapiro D, Havell EA, Huang S, Aguet M, Bosland M, and Vilcek J (1993a). Mice that lack the interferon-gamma receptor have profoundly altered responses to infection with Bacillus Calmette-Guerin and subsequent challenge with lipopolysaccharide. J Exp Med 178: 1435-1440.

Kamijo R, Shapiro D, Le J, Huang S, Aguet M, and Vilcek J (1993b). Generation of nitric oxide and induction of MHC class II antigen in macrophages from mice lacking the IFN-gamma receptor. Proc Natl Acad Sci USA 90:66266632.

Kindler V, Sappino A-P, Grau GE, Piguet P-F, and Vassalli P (1989). The inducing role of tumor necrosis factor in the development of bactericidal granulomas during BCG infection. Cell 56:731-740.

Kurihara T, Warr G, Loy J, and Bravo R (1997). Defects in macrophage recruitment and host defense in mice lacking the CCR2 chemokine receptor. J Exp Med 186:1757-1762.

Lin Y, Zhang M Barnes PF (1998). Chemokine production by a human alveolar epithelial cell line in response to Mycobacterium Tuberculosis. Infect Immun 66:1121-1126.

Lu B, Rutledge BJ, Gu L, Fiorillo J, Lukacs NW, Kunkel SL, North R, Gerard C, and Rollins BJ (1998). Abnormalities in monocyte recruitment and cytokine expression in monocyte chemoattractant protein 1-deficient mice. J Exp Med 187: 601-608.

Lucas R, Tacchini-Cottier F, Guler R, Vesin D, Jemelin S, Olleros ML, Marchal G, Browning JL, Vassalli P, and Garcia I (1999). A role for lymphotoxin beta receptor in host defense against Mycobacterium bovis BCG infection. Eur J Immunol 29:4002-4010.

MacMicking JD, North RJ, LaCourse R, Mudgett JS, Shah SK, and Nathan CF (1997). Identification of nitric oxide synthase as a protective locus against tuberculosis. Proc Natl Acad Sci USA 94:5243-5248.

Marino MW, Dunn A, Grail D, Inglese M, Noguchi Y, Richards E, and Old LJ (1997). Characterisation of tumor necrosis factor-deficient mice. Proc Natl Acad Sci USA 94:80938098.

Muller M, Eugster HP, Le Hir M, Shakhov A, Di Padova F, Maurer C, Quesniaux VFJ, and Ryffel B (1996). Correction and transfer of immunodeficiency due to TNF-LTa deletion by bone marrow transplantation. Mol Medicine 2:247-255.

Rhoades ER, Cooper AM, and Orme IA (1995). Chemokine response in mice infected with Mycobacterium tuberculosis. Infect and Immun 63:3871-3877. 
Rothe J, Lesslauer W, Lotscher H, Lang Y, Koebel P, Kontgen $F$, Althage A, Zinkernagel R, Steinmetz $M$, and Bluethmann $H$ (1993). Mice lacking the tumour necrosis factor receptor 1 are resistant to TNF-mediated toxicity but highly susceptible to infection by Listeria monocytogenes. Nature 364:798-802.

Senaldi G, Yin S, Shaklee CL, Piguet P-F, Mak TW, and Ulich TR (1996). Corynebacterium parvum- and Mycobacterium bovis bacillus Calmette-Guerin-induced granuloma formation is inhibited in TNF receptor 1 (TNF-RI) knockout mice and by treatment with soluble TNF-RI. J Immunol 157:50225026.

Smith D, Hänsch H, Bancroft G, and Ehlers S (1997). T-cellindependent granuloma formation in response to Mycobacterium avium: Role of tumour necrosis factor-alpha and interferon-gamma. Immunology 92:413-421.
Yassin RJ and Hamblin AS (1994). Altered expression of CD11/CD18 on the peripheral blood phagocytes of patients with tuberculosis. Clin Exp Immunol 97:120-125.

Zhou Y, Kurihara T, Ryseck R-P, Yang Y, Ryan C, Loy J, Warr G, and Bravo R (1998). Impaired macrophage function and enhanced $\mathrm{T}$ cell-dependent immune response in mice lacking CCR5, the mouse homologue of the major HIV-1 coreceptor. J Immunol 160:4018-4025. 